\title{
Long-term monitoring of habitats and reef fish found inside and outside the U.S. Virgin Islands Coral Reef National Monument: A comparative assessment
}

\author{
Mark E. Monaco ${ }^{1}$, Alan M. Friedlander ${ }^{2}$, Chris Caldow ${ }^{1}$, Sarah D. Hile ${ }^{1}$, \\ Charles Menza ${ }^{1}$, and Rafe H. Boulon ${ }^{3}$
${ }^{1}$ National Oceanic and Atmospheric Administration, Center for Coastal Monitoring and Assessment, Biogeography Branch, 1305 East West highway, Silver Spring, MD 20910
${ }^{2}$ US Geological Survey, Cooperative Fishery Unit, University of Hawaii, 2538 The mall, Honolulu, HI 96822 ${ }^{3}$ Virgin Islands National Park, National Park Service, 1300 Cruz Bay Creek, St. John, USVI 00830 \\ Corresponding author:mark.monaco@noaa.gov
}

\begin{abstract}
Авstract.-The primary objective of this study was to assess the efficacy of the Virgin Islands Coral Reef National Monument (VICR), a marine protected area in St John, US Virgin Islands. Surveys of habitat and fishes inside and outside of VICR were conducted in 2003-2008. Areas outside the VICR had significantly more scleractinian corals, greater habitat complexity, and greater species richness and density of reef fishes than areas inside., Areas inside and outside the VICR exhibited significant decreases in percent scleractinian coral coverage over the study period. A contrasting trend of increasing macroalgal cover was also observed. No clear effect of the severe 2005 coral bleaching event was observed suggesting other causal factors. No obvious trends in the fish community were observed across the study period. The significant decline in habitat condition, coupled with the initial incorporation of some of the more degraded reefs into the marine protected area may result in a longer time period necessary to detect positive changes in the St. John coral reef ecosystem and associated reef fish abundance and community structure.
\end{abstract}

KEYWORDS.-coral reefs, marine protected areas, marine reserves, reef fish, US Virgin Islands

\section{INTRODUCTION}

Marine protected areas (MPA) are an important tool for management of marine ecosystems (Sladek-Nowlis and Friedlander 2004). Marine reserves or "no-take" areas are part of spectrum of management mechanisms under the umbrella of MPAs (Sobel and Dahlgren 2004). Potential benefits include conservation of biodiversity, protection of individual populations, habitat protection, fishery management and tourism. To realize these benefits and maximize the likelihood for success of a given MPA, a multitude of social, economic and ecological factors must be considered prior to designation. While social and or economic criteria are frequently the impetus for MPA designation, ecological criteria are often not considered or not feasible to implement. This omission can have a substantial impact on MPA efficacy when considering eco- logical goals, such as protection of ecosystems (Sladek-Nowlis and Friedlander 2004; Monaco et al. 2007).

The Virgin Islands Coral Reef National Monument (VICR) is a MPA that is primarily a no-take marine reserve designated by US President Clinton on January 17, 2001 under the Antiquities Act of 1906 (34 Stat. 225, 16 U.S.C. 431). It is comprised of many tropical marine habitats, including fringing mangroves, seagrass beds, nearshore coral reefs, a mid-shelf reef (MSR) structure and deep water algal plains (Kendall et al. 2001). The VICR was established to preserve and protect each of these elements, as well as to further the protection of coastal and submerged ecosystems in the adjacent Virgin Islands National Park (VINP). Provisions within the Presidential Proclamation prohibit all extractive uses with the exception of fishing for a coastal pelagic species, blue 
runner (Caranx crysos) south of St. John and bait fishing in a small area within Coral Bay (CB). In addition, boat anchoring is prohibited in VICR, except for emergency or authorized administrative purposes (Boulon et al. 2008).

Resources in VINP have declined dramatically over the past few decades (Beets and Rogers 2000; Rogers and Beets 2001). The National Park Service (NPS), the National Oceanic and Atmospheric Administration (NOAA), and the US Geological Survey (USGS) initiated a joint project in 2002 to develop a baseline characterization of species and their associated habitats within and outside VICR to assess ecological changes within the ecosystem. The project objectives have evolved to monitor the efficacy of the MPA. Results from the baseline assessment along the MSR portion of the reserve revealed reef and fish community conditions were better (i.e., higher coral cover, structural complexity, fish biomass, density and richness) in areas outside and adjacent to the VICR (Monaco et al. 2007; Boulon et al. 2008). Since the reserve was delineated based on legal parameters of the Antiquities Act that defined federal waters rather than with an emphasis on ecological criteria, areas with the best resource conditions were left open to fishery harvest. The result is that detectable ecosystem improvements within the reserve may take longer to realize since the value of ecological metrics are significantly lower when compared to the same metrics in US Virgin Island Territorial waters (Monaco et al. 2007). The current paper expands on the previous studies by Monaco et al. (2007) and Boulon et al. (2008) by providing: 1) an updated assessment of the marine resources inside compared to outside the VICR along the MSR for the study period (2003-2008); 2) a comparison with the results obtained within $\mathrm{CB}$ over the same duration; and 3) temporal analysis of fish and habitat metrics to evaluate the efficacy of the MPA.

\section{Methods}

The submerged lands of the VICR consist of about $51 \mathrm{~km}^{2}$ of marine habitat off the island of St. John, US Virgin Islands (USVI) and are managed by the Secretary of the Department of the Interior through NPS. The MPA is divided into three components: two areas along the northeastern and southern portions of the VINP and an area inside CB (hereafter referred to as VICR-CB; Fig. 1). The southern component of VICR contains two sections of the MSR (hereafter referred to as VICR-MSR), which extends as a linear feature from south of St. Thomas to south of St. John. The MSR is closest to land near a promontory in southeast St. John known as Ram's Head and extends SW away from shore. The MSR is unique to the area, owing to its relatively deep (17-35 m) coral reef ecosystem and relatively high percent live coral cover and topographic complexity. The southeastern component of VICR, including the MSR, is bisected by a $0.5-1 \mathrm{~km}$ wide wedge of unprotected submerged land. This wedge extends out from shore from privately owned lands that are not included in the VINP. The CB component of the study represents a very different suite of habitats when compared to the MSR, such as patch reefs and very shallow back reef areas with low wave energy.

Based on monitoring objectives and environmental characteristics a comprehensive sampling design and suite of consistent methodologies were developed to characterize and monitor habitat and fish assemblages inside and outside VICR Monaco et al. 2007; Boulon et al. 2008). Sampling took place in the areas within safe repetitive diving limits along the MSR and inside CB (Fig. 1). (Sites were selected using a random stratified approach on hardbottom areas inside of and adjacent to MPA boundaries. The number of sites per year sampled was based on analysis of previous data collection efforts and the objective of obtaining a coefficient of variation below $20 \%$ for monitored metrics (Menza et al. 2006). Hardbottom habitat was delineated using a fine scale bathymetric surface derived from NOAA depth soundings and multibeam surveys (2004-05) off the NOAA ship Nancy Foster on the MSR (Fig. 1) and NOAA benthic habitat maps (Kendall et al. 2001) in $\mathrm{CB}$. 


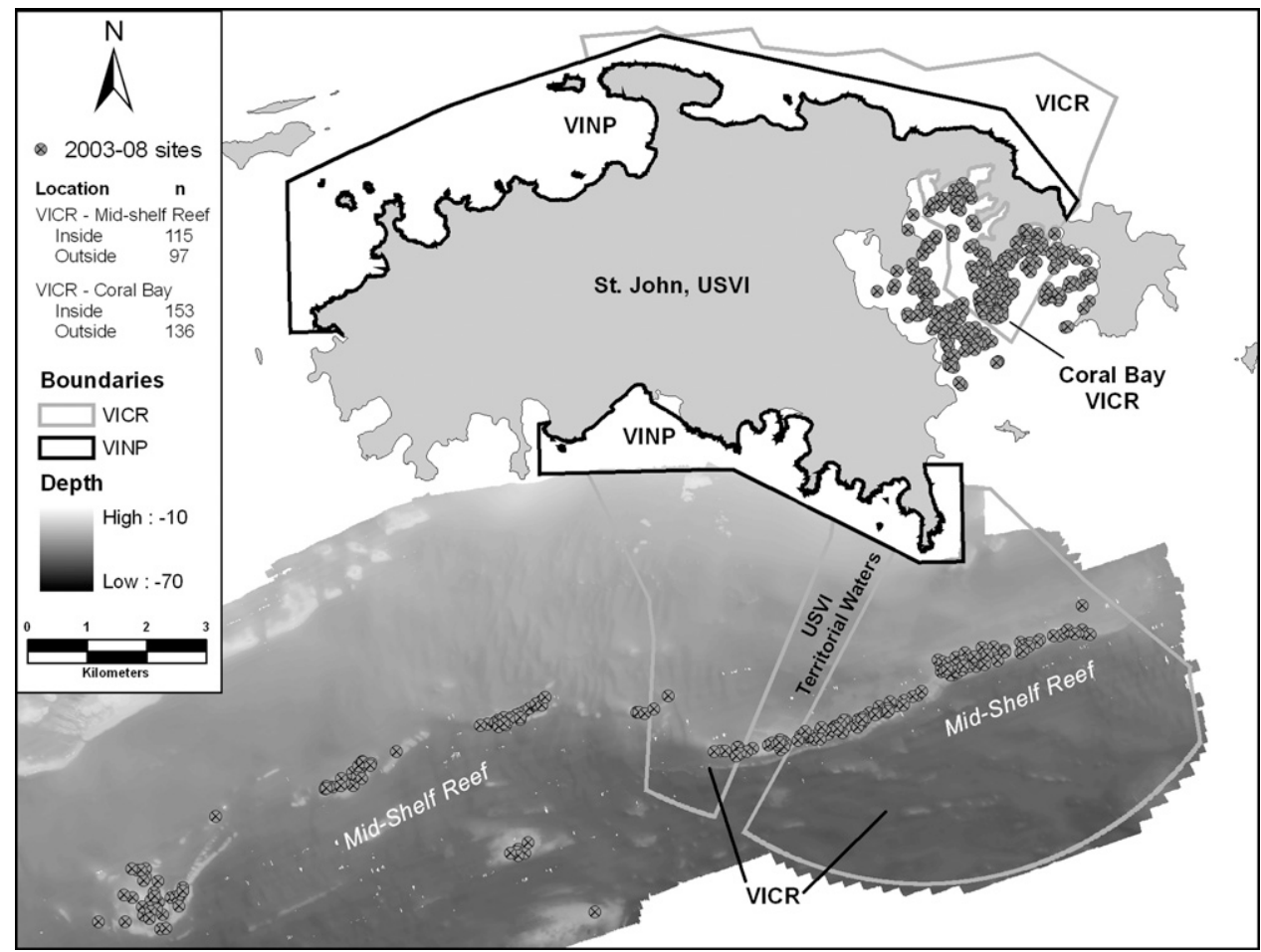

FIG. 1. Boundaries of Virgin Islands National Park (VINP) and Virgin Islands Coral Reef National Monument (VICR) and survey locations inside and outside VICR-MSR and VICR-CB from 2003-2008 in St. John, US Virgin Islands.

\section{Fish survey methods}

Reef fish and habitat data were collected annually in July from 2003 to 2008 by highly trained SCUBA divers in habitat and fish survey methods. Table 1 provides sample sizes among the four sampled strata. Sample sizes were sufficient to keep coefficient of variation below $20 \%$ for fish density and biomass and below $5 \%$ for richness.

The methods used to arrive at the fish and habitat metrics from survey data are described in Menza et al. (2006). Fish assemblages at each location (i.e., station) were assessed using standard underwater visual belt transect survey methods (Brock 1954). A SCUBA diver swam a single 25x4 m transect over 15 minutes and identified to the lowest possible taxon all fishes visible within $2 \mathrm{~m}$ to either side of the centerline (100 $\mathrm{m}^{2}$ transect area) (Monaco et al. 2007). Derived fish assemblage characteristics were species richness, density, and biomass. Biomass estimates were
TABLE 1. Number of survey sites by year and location inside or outside the VICR-MSR and VICR-CB; St. John, USVI.

\begin{tabular}{cccccc}
\hline \hline & \multicolumn{2}{c}{ MSR } & & \multicolumn{2}{c}{ CB } \\
\cline { 2 - 3 } \cline { 5 - 6 } Year & Outside & Inside & & Outside & Inside \\
\hline 2003 & 18 & 18 & & 18 & 18 \\
2004 & 18 & 18 & & 18 & 18 \\
2005 & 15 & 20 & & 25 & 30 \\
2006 & 15 & 20 & & 25 & 27 \\
2007 & 15 & 20 & & 25 & 30 \\
2008 & 16 & 19 & & 25 & 30 \\
\hline
\end{tabular}

calculated from live weight $(W)$ values derived from visually estimated mean fork length (FL) for each $5 \mathrm{~cm}$-size class for each species using the relation $W=a(\mathrm{FL})^{b}$. Values of the parameters $a$ and $b$ for each species were derived from the literature (Monaco et al. 2007). Biomasses of all fishes recorded in all surveys were obtained by multiplying the mean live weight for each size class for each species by the total number of 
individuals observed in a size class. Biomass estimates were computed without sharks and rays (very few present) and density estimates were computed without the species Coryphopterus personatus/hyalinus or herrings (Family Clupeidae), because of their unbalanced contribution to the corresponding metrics.

\section{Habitat survey methods}

As a result of limited dive time at depth, a second diver conducted a rapid assessment of fine-scale habitat quality and complexity within a 15-m diameter sampling area located at the mid-point of the transect line (Monaco et al. 2007). Benthic habitats were evaluated using five substrate and three biological metrics which describe major components of benthic cover and complexity: depth, rugosity and percent composition of hardbottom, sand, rubble, live scleractinian coral, gorgonians and macroalgae. The major habitat type was then determined based on the most prevalent biotic cover occurring within the 15-m sampling area. The minimum and maximum depth of the hard substrate within the sampling area was recorded. Rugosity, an indicator of habitat complexity, was given a value of 1-3 based on the height of the tallest hard structure: 1 if $<0.5 \mathrm{~m}$ above the seafloor; 2 if $0.5-$ to $1.5-\mathrm{m}$ tall; or 3 if $>1.5-\mathrm{m}$ tall. The percentage of area covered by abiotic substrates including hardbottom, sand and rubble was visually estimated along with the percentage of benthic cover including scleractinian coral (hard coral), gorgonians (soft coral), sponges, macroalgae and uncolonized hard substrate. Uncolonized hard substrate was defined as areas of hard substrate that contained $<10 \%$ of scleractinian or gorgonian corals.

\section{Statistical analyses}

Comparisons of benthic habitat and fish assemblage characteristics (except for fish family biomass) pooled among years within and outside VICR-MSR and VICR-CB were conducted using Student's t-tests (Zar 1984). Fish and benthic habitat metrics were compared among years and strata using analysis of variance under the GLM procedure in SAS STAT $^{\odot}$ software (SAS Institute Inc. 2009). Year (time) was used as the independent variable to identify temporal trends in each metric. Tukey's studentized range (HSD) multiple comparison test was used to test for significant differences among years in each stratum. Fish biomass and density were $\ln (x+1)$ transformed and habitat cover values were arcsine-square root transformed prior to analysis. Graphs of coral and macroalgal cover were visually examined for an effect of the 2005 coral bleaching event.

\section{Results}

\section{VICR-Mid-shelf reef}

Several habitat metrics averaged over the course of the study showed significant differences between sites inside and outside VICR-MSR (Table 2). Live scleractinian coral and rugosity were significantly greater outside the MPA, while gorgonian cover was

TABle 2. Comparison of mean ( \pm standard deviation) benthic habitat characteristics inside and outside VICRMSR the south shore of St. John, USVI (2003-2008). Percentage values were arcsine-square root transformed for statistical analysis. $P$ is the probability of no significant difference between inside and outside VICR-MSR. Asterisk $\left(^{*}\right)$ indicates significant difference $(P<0.05)$.

\begin{tabular}{|c|c|c|c|c|c|}
\hline \multicolumn{2}{|c|}{ Habitat characteristics } & \multirow{2}{*}{$\frac{\text { Outside VICR-MSR }}{86.31(8.42)}$} & \multirow{2}{*}{$\frac{\text { Inside VICR-MSR }}{85.47(6.83)}$} & \multirow{2}{*}{$\begin{array}{c}\% \text { difference } \\
-1.0\end{array}$} & \multirow{2}{*}{$\frac{P}{0.43}$} \\
\hline Abiotic & Depth (ft) & & & & \\
\hline & Rugosity & $2.27(0.66)$ & $2.04(0.79)$ & -11.3 & $0.02^{*}$ \\
\hline & Hard bottom (\%) & $85.43(8.86)$ & $85.89(16.54)$ & 0.5 & 0.06 \\
\hline & Sand $(\%)$ & $10.43(6.94)$ & $9.11(8.28)$ & -14.5 & 0.13 \\
\hline & Rubble (\%) & $4.13(4.08)$ & $3.21(5.34)$ & -28.7 & 0.07 \\
\hline \multirow[t]{3}{*}{ Biotic } & Live scleractinian coral cover $(\%)$ & $14.93(16.57)$ & $4.05(5.47)$ & -312.8 & $<0.001^{*}$ \\
\hline & Gorgonian cover $(\%)$ & $12.83(7.35)$ & $21.84(14.86)$ & 41.3 & $<0.001^{*}$ \\
\hline & Macroalgal cover $(\%)$ & $47.07(18.92)$ & $44.35(21.64)$ & -6.1 & 0.27 \\
\hline
\end{tabular}


greater inside. Although the component coral cover groups (scleractinian and gorgonian) are different, total coral cover among areas is similar.

Throughout the study period, mean coral cover showed a substantial decrease over time (Fig. 2). This trend was particularly evident outside the MPA where cover declined by $85 \%$ from 2003 to 2007 with a slight increase in 2008. Similarly a decrease of $78 \%$ was observed inside the MPA
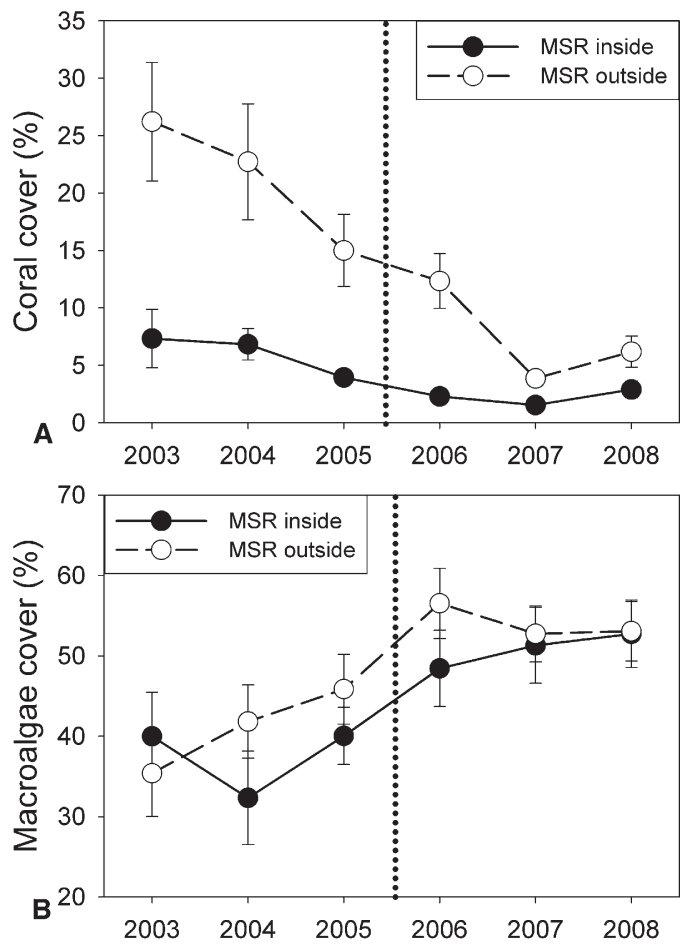

FIG. 2. Trends in percent (a) live scleractinian coral (b) and macro-algal cover inside and outside the VICRMSR; St. John, USVI (2003-2008). The vertical dashed line represents data collect prior to and after the 2005 coral bleaching event. between the same years; however, the initial percent cover there was less than one third of that outside. Macroalgae showed the reverse trend over time with an increase of $185 \%$ outside through 2006 followed by a slight decrease in 2007. Inside the MPA, macroalgae decreased between 2003 and 2004 and then increased by 161\% through 2008 (Fig. 2). There appeared to be no noticeable impact of the 2005 coral bleaching event on any of these trends as the decrease in coral cover and increase of algae was occurring over the entire study period (Fig. 2).

Reef fish species richness and density were significantly greater outside of the MPA (Table 3). Biomass was also greater outside, but the difference was not significant. Temporal analysis did not show any significant difference in fish biomass, either among years or a trend over all years (Table 4; Fig. 3).

\section{VICR-Coral Bay}

All but one of the abiotic habitat characteristics was similar between samples taken inside and outside of VICR-CB; the one exception was rubble cover, which was greater inside the MPA (Table 5). Two of the three investigated biotic variables were significantly different among areas inside and outside the MPA (Table 5). Live scleractinian coral was almost twice as high outside, but both values were still relatively low (i.e. $<10 \%$ ). Macroalgae cover was greater inside.

Mean coral cover inside and outside VICR-CB appeared to decrease over time with local maxima in 2005 inside the MPA (8\%) and 2004 outside (15\%) (Fig 4). In both datasets, coral cover decreased by over $60 \%$ in years subsequent to the maxima and remained low through the end of the

TABLE 3. Comparison of mean ( \pm standard deviation) fish assemblage characteristics inside and outside VICRMSR along the south shore of St. John, USVI (2003-08). $P$ is the probability of no significant difference between inside and outside VICR-MSR. Density and biomass were log transformed $\ln (x+1)$ for statistical analyses. Asterisk $\left(^{*}\right)$ indicates significant difference $(P<0.05)$.

\begin{tabular}{lcccc}
\hline \hline Fish assemblage characteristics & Outside VICR-MSR & Inside VICR-MSR & \% difference & P value \\
\hline Species richness $\left(\#\right.$ species $\left./ 100 \mathrm{~m}^{2}\right)$ & $27.42(5.576)$ & $23.83(4.28)$ & -15.095 & $<0.0001^{*}$ \\
Density $\left(\#\right.$ individuals $\left./ 100 \mathrm{~m}^{2}\right)$ & $293.91(226.36)$ & $228.64(139.36)$ & -28.544 & $0.0178^{*}$ \\
Biomass $\left(\mathrm{g} / 100 \mathrm{~m}^{2}\right)$ & $8773.10(6754.67)$ & $7900.64(7002.19)$ & -11.043 & 0.11 \\
\hline
\end{tabular}


TABLE 4. Results of trend analysis for fish assemblage characteristics inside and outside VICR-MSR; St. John, USVI. Density and biomass were $\log$ transformed $\ln (x+1)$ for statistical analyses.

\begin{tabular}{|c|c|c|c|c|c|c|}
\hline \multirow[b]{2}{*}{ Fish assemblage characteristics } & \multicolumn{3}{|c|}{ Outside VICR-MSR } & \multicolumn{3}{|c|}{ Inside VICR-MSR } \\
\hline & Slope & $\mathrm{R}^{2}$ & P value & Slope & $\mathrm{R}^{2}$ & P value \\
\hline Species richness (\# species /100 m²) & -0.11 & 0.00 & 0.75 & 0.16 & 0.00 & 0.50 \\
\hline Density (\# individuals /100 m²) & -0.01 & 0.00 & 0.74 & 0.00 & 0.00 & 0.87 \\
\hline Biomass $\left(\mathrm{g} / 100 \mathrm{~m}^{2}\right)$ & -0.05 & 0.02 & 0.13 & -0.05 & 0.02 & 0.17 \\
\hline
\end{tabular}

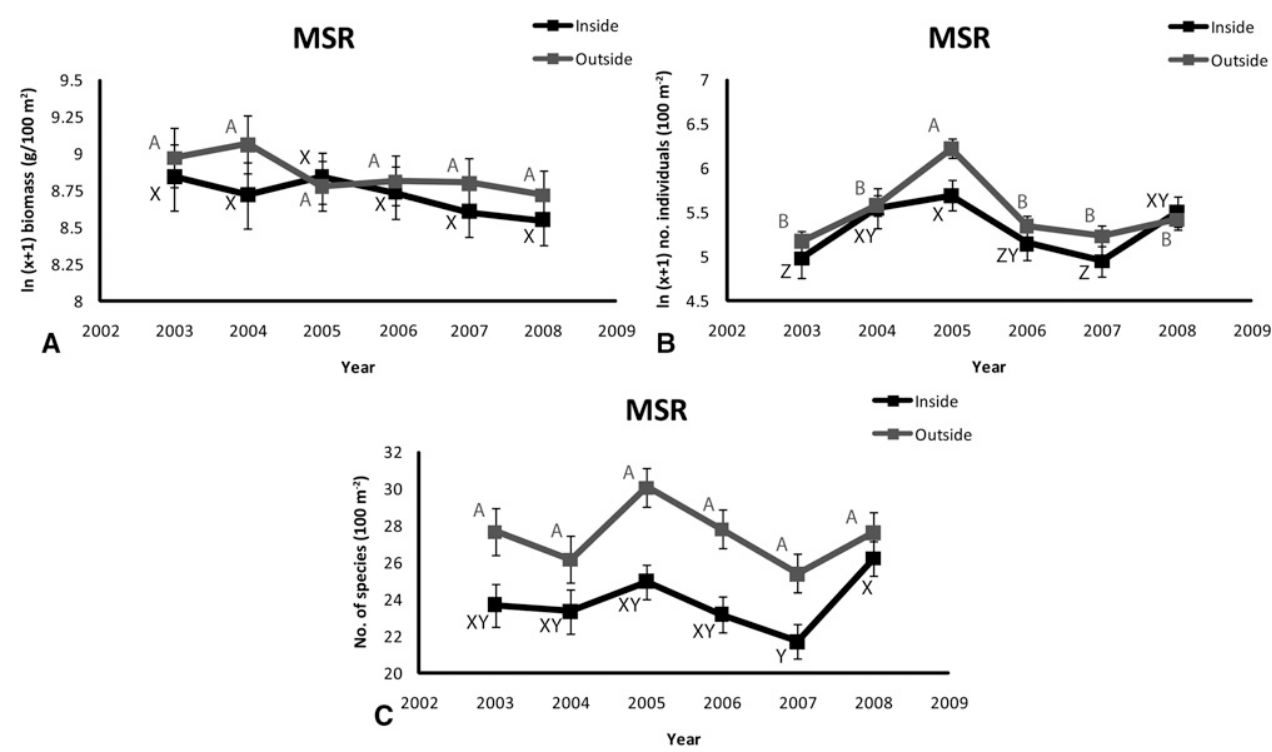

FIG. 3. Temporal trends in fish (a) biomass, (b) abundance, and (c) species richness inside and outside the VICR-MSR; St. John, USVI (2003-2008). Means with the same letter designations are not significantly different ( $>0.05$ ) by the Tukey HSD test. ABC and XYZ letters used for outside and inside the Monument, respectively. Note: the HSD tests do not compare inside versus outside.

TABle 5. Comparison of mean ( \pm standard deviation) benthic habitat characteristics inside and outside VICR-CB; St. John, USVI (2003-2008). Percentage values were arcsine-square root transformed for statistical analysis. $P$ is the probability of no significant difference between inside and outside VICR-CB. Asterisk $\left(^{*}\right)$ indicates significant difference $(P<0.05)$.

\begin{tabular}{|c|c|c|c|c|c|}
\hline \multicolumn{2}{|c|}{ Habitat characteristics } & \multirow{2}{*}{$\frac{\text { Outside VICR-CB }}{37.65(23.60)}$} & \multirow{2}{*}{$\frac{\text { Inside VICR-CB }}{33.53(13.17)}$} & \multirow{2}{*}{$\frac{\% \text { difference }}{-12.3}$} & \multirow{2}{*}{$\frac{\mathrm{P}}{0.08}$} \\
\hline Abiotic & Depth (ft) & & & & \\
\hline & Rugosity & $2.31(0.73)$ & $2.18(0.77)$ & -6.0 & 0.17 \\
\hline & Hard bottom (\%) & $67.11(25.23)$ & $61.76(21.95)$ & -8.7 & 0.06 \\
\hline & Sand $(\%)$ & $23.85(20.51)$ & $26.19(17.12)$ & -8.9 & 0.24 \\
\hline & Rubble (\%) & $9.04(12.77)$ & $12.05(12.59)$ & 25.0 & $0.005^{*}$ \\
\hline \multirow[t]{3}{*}{ Biotic } & Live scleractinian coral cover $(\%)$ & $8.09(8.02)$ & $4.41(5.71)$ & -83.4 & $<0.001^{*}$ \\
\hline & Gorgonian cover $(\%)$ & $11.20(10.91)$ & $12.21(13.20)$ & 8.3 & 0.86 \\
\hline & Macroalgal cover $(\%)$ & $30.35(16.00)$ & $36.68(22.28)$ & 17.3 & $0.01^{*}$ \\
\hline
\end{tabular}

series. Inter-annual changes in both data series showed similar changes with a one year offset. Macroalgae cover increased during the study period inside the MPA in a pattern similar to MSR, but the pattern was more variable outside. Highest macroalgal cover was observed in 2008 throughout CB. As with the MSR, no clear 
influence of the 2005 coral bleaching event was detected.

Average species richness, fish density and biomass estimates were not different among samples inside and outside of the MPA (Table 6). Temporal analysis showed a significant increase in biomass between 2005 and 2006 and then subsequent decrease between 2006 and 2008 outside the MPA (Fig. 5). A significant negative trend in biomass outside was observed using all years (Table 7). Similar changes in species richness
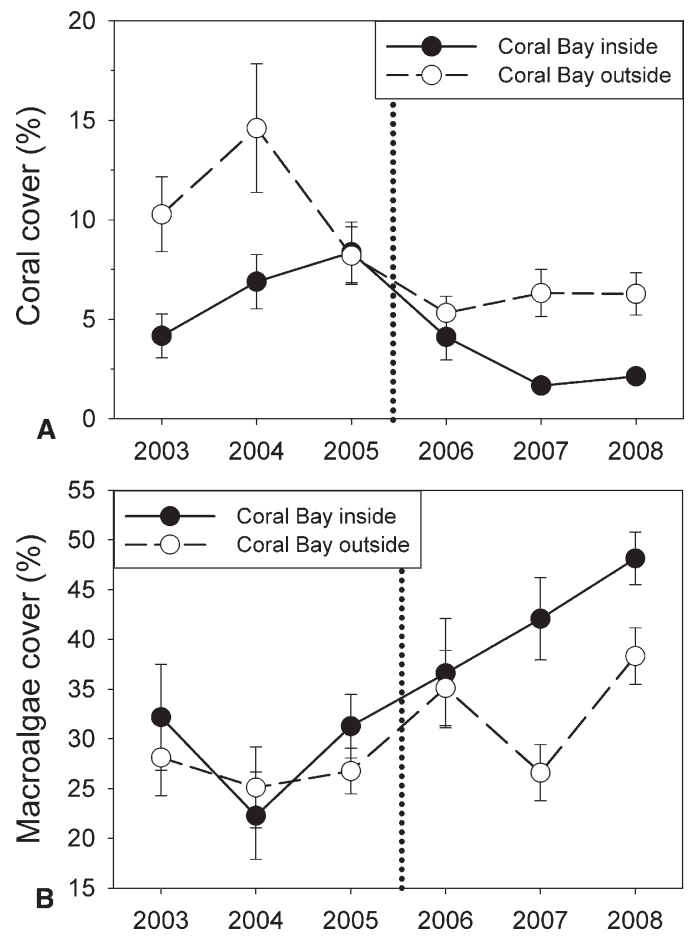

FIG. 4. Trends in percent (a) live scleractinian coral (b) and macroalgal cover inside and outside the VICR-CB; St. John, USVI (2003-2008). Vertical dashed line represents data collect prior to and after the 2005 coral bleaching event. or fish density outside, or fish biomass inside were not observed. In contrast, the inter-annual temporal changes corresponding to biomass, fish density and species richness inside the MPA were tightly coupled. All three fish metrics corresponding to samples taken from inside showed a temporary minimum in 2004 followed by a maximum in 2005. These extremes were not significantly different than the rest of the years (Fig. 5) and no significant study-long trend was found (Table 7).

The dissimilarity between fish biomass and density in CB warranted further investigation since biomass is a function of fish density (i.e., more fish = more biomass). An examination of the species and size of fish observed in CB show the changes in biomass relate to the presence of large-bodied fish or large schools of fish seen in years with high biomass. We found six of the seven samples with highest biomass were collected in 2006. Each of these samples either had large great barracuda (Sphyraena barracuda; $>90 \mathrm{~cm}$ ) or large schools $(>50$ individuals) of medium-sized $(10-15 \mathrm{~cm})$ grunts (Family Haemulidae) or both. Large individual fish (e.g., $>50 \mathrm{~cm}$ ) and schools of fish that are infrequently encountered can greatly amplify biomass estimates. In 2008, the year with the lowest biomass, no large great barracuda $(>80 \mathrm{~cm})$ or large schools of medium-sized grunts were observed.

\section{DISCUSSION}

This paper provides the first assessment of VICR efficacy when compared to similar areas with limited protection in USVI Territorial waters. This assessment builds on the baseline data presented by Monaco et al. (2007) for the VICR-MSR and Boulon et al. (2008) with an extended dataset and

TABLE 6. Comparison of mean ( \pm standard deviation) fish assemblage characteristics inside and outside VICRCB; St. John, USVI (2003-08). P is the probability of no significant difference between inside and outside VICR-CB. Density and biomass were $\log$ transformed $\ln (x+1)$ for statistical analyses. Asterisk $\left(^{*}\right)$ indicates significant difference $(P<0.05)$.

\begin{tabular}{lccrc}
\hline \hline Fish assemblage characteristics & Outside VICR-CB & Inside VICR-CB & \% difference & P value \\
\hline Species richness $\left(\#\right.$ species $\left./ 100 \mathrm{~m}^{2}\right)$ & $22.55(5.27)$ & $21.91(5.15)$ & -2.935 & 0.29 \\
Density $\left(\#\right.$ individuals $\left./ 100 \mathrm{~m}^{2}\right)$ & $149.13(74.63)$ & $149.15(99.49)$ & 0.017 & 0.99 \\
Biomass $\left(\mathrm{g} / 100 \mathrm{~m}^{2}\right)$ & $4871.09(4237.17)$ & $5207.37(5255.80)$ & 6.458 & 0.93 \\
\hline
\end{tabular}




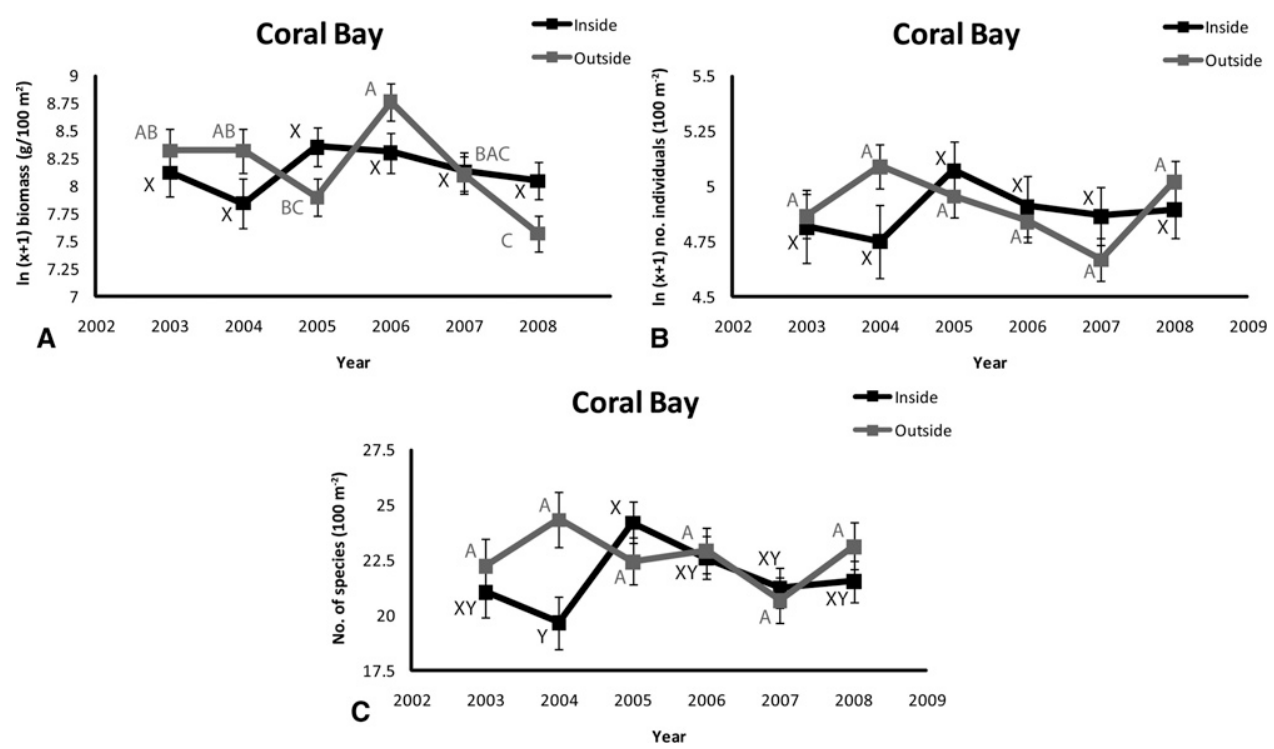

FIG. 5. Temporal trends in fish (a) biomass, (b) abundance, and (c) species richness inside and outside the VICR-CB; St. John, USVI1 (2003-2008). Means with the same letter designations are not significantly different ( $>0.05$ ) by the Tukey HSD test. ABC and XYZ letters used for outside and inside the Monument, respectively. Note: the HSD tests do not compare inside versus outside.

TABLE 7. Results of trend analysis for fish assemblage characteristics inside and outside VICR-CB; St. John, USVI. Density and biomass were $\log$ transformed $\ln (\mathrm{x}+1)$ for statistical analyses. Asterisk $\left(^{*}\right)$ indicates significant difference $(P<0.05)$.

\begin{tabular}{|c|c|c|c|c|c|c|}
\hline \multirow[b]{2}{*}{ Fish assemblage characteristics } & \multicolumn{3}{|c|}{ Outside VICR-CB } & \multicolumn{3}{|c|}{ Inside VICR-CB } \\
\hline & Slope & $\mathrm{R}^{2}$ & P value & Slope & $\mathrm{R}^{2}$ & P value \\
\hline Species richness (\# species /100 m²) & -0.17 & 0.00 & 0.55 & 0.07 & 0.00 & 0.88 \\
\hline Density (\# individuals $/ 100 \mathrm{~m}^{2}$ ) & -0.02 & 0.00 & 0.51 & 0.01 & 0.00 & 0.07 \\
\hline Biomass $\left(\mathrm{g} / 100 \mathrm{~m}^{2}\right)$ & -0.11 & 0.04 & $0.02 *$ & 0.00 & 0.00 & 0.99 \\
\hline
\end{tabular}

incorporates an assessment of the Coral Bay component of the VICR. Additionally, information on the trends in benthic habitats and reef fish community structure since 2003 is presented along with information to assess the relatively short-term impacts of the 2005 coral bleaching event in the US Caribbean (Clark et al. 2009).

\section{VICR-Mid-shelf reef}

Observations made during the course of this study (2003-2008) show an alarming trend of declining coral cover across the entire MSR regardless of management strata since the study was initiated. Monaco et al. (2007) reported that for the study period
(2002-2004) significantly greater live scleractinian coral cover was observed outside VICR-MSR with a mean of $25 \%$ compared to only $8 \%$ inside. In 2008 , the most recent year examined, scleractinian coral cover was $6 \%$ outside and $3 \%$ inside, demonstrating convergence in live coral cover across management areas to relatively low values. While the trend is particularly evident for the area outside of the VICR-MSR this is primarily due to the relatively low starting point inside the VICR-MSR. Also of note, macroalgal cover appears to be replacing the coral potentially as a result of competitive release for space.

Although there have been dramatic changes in the variables describing habitat 
on the MSR, including a significant decrease in the amount of live coral cover, fish community metrics have remained relatively unchanged. This stability suggests the fish community is not immediately affected by observed changes in habitat; however only long-term monitoring programs such as the one used to analyze this data will be able to determine if the fish community will change in the future.

It is imperative that the results of contemporary investigations be viewed with the knowledge that large changes in the USVI coral ecosystems occurred prior to the establishment of long-term monitoring studies, including the current investigation. Large predators, such as groupers and snappers, are now in low abundance compared to documented investigations in the 1950s-60s (Beets and Rogers, 1997, Rogers and Beets 2001, Friedlander and Beets 2008). Monaco et al. (2007) found snappers (e.g., Lutjanus analis, mutton snapper) were not abundant inside or outside of the VICR-MSR as they only represented $3 \%$ of the total fish biomass along the mid-shelf reef. In addition, they reported that only two tiger groupers (Mycteroperca tigris) accounted for $10 \%$ of the total large grouper biomass along the mid-shelf reef study area. Thus, the fact the current investigation did not see large changes overtime of reef fish metrics is not surprising given the shifted baseline of reef fish populations in the near shore waters of the USVI (Friedlander and Beets 2008).

\section{VICR-Coral Bay}

While live scleractinian coral cover was greater outside of VICR-CB compared to inside, it was not as dramatic as the difference along the MSR. The trends in both coral and macroalgal cover, while more variable than in the MSR, were in the same direction across management strata. A mosaic of hardbottom habitats is found in $\mathrm{CB}$, including patch reefs, linear reefs and bedrock (Kendall et al. 2001). Some of the between year variability may be explained by the diversity of habitats which are sampled using a random design. The mean values for live scleractinian coral cover of $6 \%$ outside and $2 \%$ inside are nearly identical to those along the MSR. This convergence across management strata and locations to a degraded reef condition has the potential to seriously impact the larger ecosystem by reducing the diversity of habitat available to a variety of organisms.

Interestingly, in spite of its documented impact on selected reef systems particularly in the USVI and Puerto Rico (Miller et al. 2009), there is no obvious sign of impact from the massive 2005 coral bleaching event across any of the strata. In $\mathrm{CB}$, some portion of the mortality may be related to the increased development around the bay and therefore increased sedimentation and decreased light levels. The areas of the MSR where coral cover declined the most however were far from shore $(>3 \mathrm{~km})$, and thus other stessors are likely responsible for the declines observed inside and outside VICR-MSR (e.g., coral disease, reduction of fish herbivores, increased sedimentation, increased seawater temperatures, and storm events) (Miller et al. 2009; Jeffrey et al. 2005; Rothenberger et al. 2008).

The significant decline in habitat condition, coupled with the initial incorporation of some of the more degraded reefs into the MPA may further increase the time period necessary to detect positive changes in the St. John coral reef ecosystem and associated reef fish abundance and community structure. This assumes that the decline in reef fish biomass and habitats may be somewhat reversed by implementing and enforcing the management regulations of the VICR.

The inter-annual variability in the data observed in this study emphasizes the necessity of long-term data sets for interpreting the results and for detecting real and meaningful trends. Plans are to continue the long-term monitoring of hard bottom habitats within and outside the VICR-MSR and VICR-CB. One area of study emphasis will be to investigate if the dramatic changes in the quality of benthic habitats can be correlated to changes in reef fish populations for specific species, families, or the entire reef fish community found inside and outside the VICR.

Acknowledgements.-This study was made possible by the dedicated efforts of NOAA's 
Center for Coastal Monitoring and Assessment and the National Park Service. Funding was provided by CCMA, NPS, USGS, and NOAA's Coral Reef Conservation Program. Additional field support was provided by J. Beets, R. Clark, A. Davis, K. Foley, C. Jeffrey, M. Kendall, J. Miller, C. Rogers, J. Waddell, R. Waara and K. Woody.

\section{Literature Cited}

Beets, J., and C. Rogers. 1997. Can coral reef fish assemblages be sustained as fishing intensity increases? Proc. $8^{\text {th }}$ Int. Coral Reef Symp. 2:2009-2014.

Beets, J., and C. Rogers. 2000. Changes in fishery resources and reef fish assemblages in a Marine Protected Area in the US Virgin Islands: the need for a no take marine reserve. Proc. $9^{\text {th }}$ Int. Coral Reef Symp. 1:449-454.

Boulon, R. H., M. E. Monaco, A. M. Friedlander, C. Caldow, J. Christensen, C. Rogers, J. Beets, J. Miller, and S. D. Hile. 2008. An ecological correction to marine reserve boundaries in the US Virgin Islands. Proc. 11 ${ }^{\text {th }}$ Int. Coral Reef Symp. Pp. 1074-1077.

Brock, V. E. 1954. A preliminary report on a method of estimating reef fish populations. J. Wildl. Manage. 18(3):397-308.

Clark, R., C. Jeffrey, K. Woody, Z. Hillis-Starr, and M. Monaco. 2009. Spatial and temporal patterns of coral bleaching around Buck Island Reef National Monument, St. Croix, U.S. Virgin Islands. Bull. Mar. Sci. 84(2):167-182.

Friedlander, A. M., and J. Beets. 2008. Temporal trends in reef fish assemblages inside Virgin Islands National Park and around St. John, U.S. Virgin islands, 19882006. NOAA Tech. Memo. NOS NCCOS 70:1-60.

Jeffrey, C. F. G., U. Anlauf, J. Beets, S. Caseau, W. Coles, A. M. Friedlander, S. Herzlieb, Z. Hillis-Starr, M. Kendall, V. Mayor, J. Miller, E. Nemeth, C. Rogers, and W. Toller. 2005. The state of coral reef ecosystems of the U.S. Virgin Islands. In The state of coral reef ecosystems of the United States and Pacific Freely Associated States: 2005, ed. J. Waddell, 45-90. NOAA Tech. Memo. NOS NCCOS 11

Kendall, M., M. E. Monaco, K. R. Buja, J. D. Christensen, C. R. Kruer, M. Finkbeiner, and R. A. Warner. 2001. (On-line). Methods Used to Map the Benthic Habitats of Puerto Rico and the U.S. Virgin Islands.
NOAA Tech. Memo. NOS NCCOS CCMA 152:1-49. http: / / ccma.nos.noaa.gov/products / biogeogra phy/benthic/welcome.html

Menza, C., J. Ault, J. Beets, J. Bohnsack, C. Caldow, J. Christensen, A. Friedlander, C. Jeffrey, M. Kendall, J. Luo, M. Monaco, S. Smith, and K. Woody. 2006. A Guide to Monitoring Reef Fish in the National Park Service's South Florida / Caribbean Network. NOAA Tech. Memo. NOS NCCOS 39:1-166.

Miller, J., E. Muller, C. Rogers, R. Waara, A. Atkinson, K. R. T. Whelan, M. Patterson, and B. Witcher. 2009. (Online). Coral disease following massive bleaching in 2005 causes $60 \%$ decline on coral cover on reefs in the U.S. Virgin Islands. Coral Reefs. http:/ / www. springerlink.com/content/t8474w3380q1814q/ fulltext.pdf

Monaco, M., A. M. Friedlander, C. Caldow, J. D. Christensen, C. Rogers, J. Beets, J. Miller, and R. Boulon. 2007. Characterizing reef fish populations and habitats within and outside of the US Virgin Islands Coral Reef National Monument: a lesson in marine protected area design. Fish. Manag. Ecol. 14(1):33-40.

Rogers, C., and J. Beets. 2001. Degradation of marine ecosystems and decline of fishery resources in marine protected areas in the US Virgin Islands. Environ. Conserv. 28(4):312-322.

Rothenberger, P., J. Blondeau, C. Cox, S. Curtis, W. S. Fisher, V. Garrison, Z. Hillis-Starr, C. F. G. Jeffrey, E. Kadison, I. Lundgren, W. J. Miller, E. Muller, R. Nemeth, S. Paterson, C. Rogers, T. Smith, A. Spitzack, M. Taylor, W. Toller, J. Wright, D. Wusinich-Mendez, and J. Waddell. 2008. The state of coral reef ecosystems of the U.S. Virgin Islands. In The state of coral reef ecosystems of the United States and Pacific Freely Associated States: 2008, ed. J. Waddell, and A. M. Clarke, 29-73. NOAA Tech. Memo. NOS NCCOS 73.

SAS Institute, Inc. 2009. SAS/STAT ${ }^{\odot}$ Software. North Carolina: SAS Institute, Inc.

Sladek-Nowlis, J., and A. M. Friedlander. 2004. Design and designation of marine reserves. In Marine reserves: a guide to science, design, and use, eds. J. A. Sobel, and C. P. Dahlgren, 128-163. Washington D.C.: Island Press.

Sobel, J. A., and C. P. Dahlgren. 2004. Marine Reserves: a guide to science, design, and use. Washington D.C.: Island Press.

Zar, J. H. 1984. Biostatistical analysis, $2^{\text {nd }}$ ed. New Jersey: Prentice-Hall. 